\title{
Armadilhas fotográficas e o monitoramento remoto da biodiversidade
}

\section{Flávio Kulaif Ubaid}

Laboratório de Ornitologia, Centro de Estudos Superiores de Caxias, Universidade Estadual do Maranhão, Brasil Correspondencia: flavioubaid@gmail.com

\section{INTRODUÇÃO}

Instintivamente, o ser humano sempre demonstrou interesse pelas espécies que o cercam. Isto é facilmente constatado na história das civilizações em qualquer canto do planeta. Tentativas de retratar o cotidiano em paredes de cavernas e papel são recorrentes na história da humanidade e aparecem de maneira independente em diversos momentos da história.

Identificar as espécies de determinado local, compreender seus comportamentos, padrões de distribuição, interações e outros aspectos da história natural impulsionaram os grandes naturalistas a desbravar áreas até então desconhecidas cientificamente e permeiam toda a história das ciências naturais. Os trabalhos primorosos de Carolus Linnaeus e Charles Darwin, entre tantos outros naturalistas, são exemplos que ultrapassaram o meio das ciências naturais e se tornaram reconhecidos em muitas outras disciplinas.

Um dos aspectos em comum das obras de Linnaeus e Darwin é a retratação das espécies e seus comportamentos por meio de imagens. Linnaeus não teve a oportunidade de desfrutar da tecnologia fotográfica e apresentou em sua obra inúmeras ilustrações, aliás de excelente qualidade. Já Darwin, que presenciou o surgimento da fotografia em papel, pôde utilizá-la em vários momentos. A fotografia teve papel importante, 
particularmente, em "The expression of the emotions in man and animals", publicado em 1872, onde ele apresenta suas observações sobre como o ser humano e os animais expressam suas emoções.

Desde então, um século e meio se passou e o desenvolvimento tecnológico forneceu novas ferramentas para o estudo e monitoramento da vida na Terra. Uma dessas ferramentas tem recebido grande e crescente atenção por parte da comunidade científica e se destacado por suas possibilidades de aplicação: trata-se do monitoramento remoto da biodiversidade por meio de fotografias. Reconhecidas as suas infinitas possibilidades de aplicação, desde o sensoriamento remoto com imagens de satélite até a exploração de zonas abissais em submersíveis não tripulados, este breve ensaio trata apenas do uso da fotografia remota no monitoramento de animais terrestres.

\section{EVOLUÇÃO}

A utilização de dispositivos de fotografia remota para a documentação da biodiversidade tem uma história relativamente longa em pesquisas ecológicas. Uma das primeiras fotografias disparadas por um animal foi obtida em 1878, quando um cavalo galopando desencadeou um sistema de fios conectados a uma dúzia de câmeras. Este experimento estabeleceu dois importantes marcos: permitiu a compreensão, de maneira mais rigorosa, da locomoção animal, demonstrando que o animal mantinha as quatro patas fora do chão em certos momentos do galope (Guggisberg, 1977); e foi um dos primeiros exemplos em que um animal tirou sua própria foto (Kucera e Barrett, 2011).

$\mathrm{Na}$ década de 1890, o norteamericano George Shiras desenvolveu um método inovador usando o sistema de fios de disparo em conjunto com um sistema de flash. Com base em seu conhecimento prévio sobre o comportamento das espécies, ele adaptou diversos sistemas para induzir o animal a puxar o fio, como por exemplo o uso de iscas ou objetos de interesse dos animais amarrados ao fio. Foi assim que ele registrou inúmeras espécies de animais selvagens (Guggisberg, 1977). Experiência semelhante foi conduzida pelo 
Frei Wilhelm Schüte Witte, ou Frei Miguel, em 1931 no estado do Paraná (Witte, 1931).

No entanto, esta tecnologia foi de uso restrito (ver Kucera e Barrett 2011) até o surgimento das câmeras com sensores de infravermelho, na década de 1980. A partir de então as câmeras se tornaram comercialmente disponíveis, mais leves e fáceis de operar.

Em meados da década de 1990, sua utilização em larga escala possibilitou os primeiros estudos ligados à análise de captura-recaptura para estimar a abundância de animais.

O início do século XXI marcou a popularização da tecnologia das câmeras digitais. Além de fotografias, muitos modelos são capazes de gravar vídeos, inclusive com áudios, que são armazenados diretamente em um cartão de memória.

A popularização dos equipamentos fotográficos elevou ainda mais a qualidade das fotografias obtidas remotamente. Hoje há um número crescente de profissionais utilizando câmeras DSLR profissionais nesse sentido. $\mathrm{O}$ método consiste essencialmente em instalar uma câmera
DSLR em uma caixa impermeável e conectá-la a um sensor infravermelho de detecção de movimento e calor, algo como um mini estúdio instalado na floresta.

Os modelos mais modernos disponíveis atualmente contam com tecnologia $3 \mathrm{G}$ para o envio de mensagens SMS e e-mail. Isto permite o acompanhamento diário do funcionamento das câmeras, sendo necessária somente a manutenção periódica.

Quanto ao mecanismo de disparo, existem dois tipos de armadilhas fotográficas: ativas e passivas. No sistema passivo, a câmera está equipada com um sensor de "calor e movimento", que aciona a câmera quando qualquer coisa com temperatura diferente da do ambiente se move no campo de detecção do sensor. Mesmo as altas temperaturas do ambiente ou a própria vegetação aquecida pelo sol podem disparar o sistema. Entretanto, o mecanismo pode não desencadear caso a temperatura corpórea do animal e do ambiente sejam semelhantes.

Nas câmeras com sistema ativo, um feixe infravermelho é ativamente 
estabelecido em um caminho potencial de passagem dos animais e o disparo é acionado quando o feixe é interrompido. Este sistema proporciona maior flexibilidade na instalação, uma vez que a altura do feixe pode ser ajustada de acordo com as espécies alvo. No entanto, o disparo pode ser desencadeado por qualquer elemento que interrompa o feixe, incluindo pequenos animais, como insetos e aves, a vegetação em movimento e gotas de água em dias chuvosos.

Os sistemas disponíveis atualmente são, em sua maioria, de fácil operação, portáteis, duráveis e obtém imagens de alta qualidade. A concorrência gerada pelo aumento expressivo do número de fabricantes e modelos disponíveis fez com que o valor dos equipamentos caísse consideravelmente, tornando-os mais acessíveis para um número maior de interessados. O resultado foi um aumento nos estudos utilizando esta tecnologia.

\section{APLICAÇÕES}

O monitoramento remoto por meio de fotografias permite o estudo de eventos difíceis de observar através de métodos tradicionais de observação ou captura, além das vantagens envolvidas em monitoramentos de longo prazo e avaliação de espécies causadoras de conflitos. Basicamente, a fotografia remota (leia-se fotografia e/ou vídeo) é definida como a obtenção de imagens de animais selvagens na ausência do pesquisador. Estas, por sua vez, podem incluir sistemas de disparo programado (por lapso de tempo) ou desencadeados por animais.

Seu uso básico é documentar a presença de espécies dentro de determinada área. Entretanto, uma ampla variedade de objetivos de pesquisa pode ser abordada usando a fotografia remota, com exemplos espalhados na literatura. Para tanto, os objetivos de um estudo devem ser cuidadosamente delineados para que os métodos empregados sejam suficientes para responder à pergunta da pesquisa. Em estudos com armadilhas fotográficas, frequentemente se busca conhecer a diversidade de animais de médio e grande porte (normalmente mamíferos) da área de estudo; confirmar a presença de uma 
espécie em particular, geralmente rara ou ameaçada de extinção; analisar a distribuição espacial, o padrão de atividade ou a abundância de uma ou várias espécies.

As armadilhas fotográficas também têm sido utilizadas para investigar as diferenças de abundância em mosaicos com diferentes tipos de uso da terra (Kinnaird et al., 2003, Jacomo et al., 2004), assim como a determinação de fatores ecológicos que afetam o uso do habitat pelas espécies (Bowkett et al., 2007). De acordo com Kauffman et al. (2007), quando utilizadas em conjunto com outros métodos, as armadilhas fotográficas podem gerar informações refinadas em estudos ecológicos (Kauffman et al., 2007).
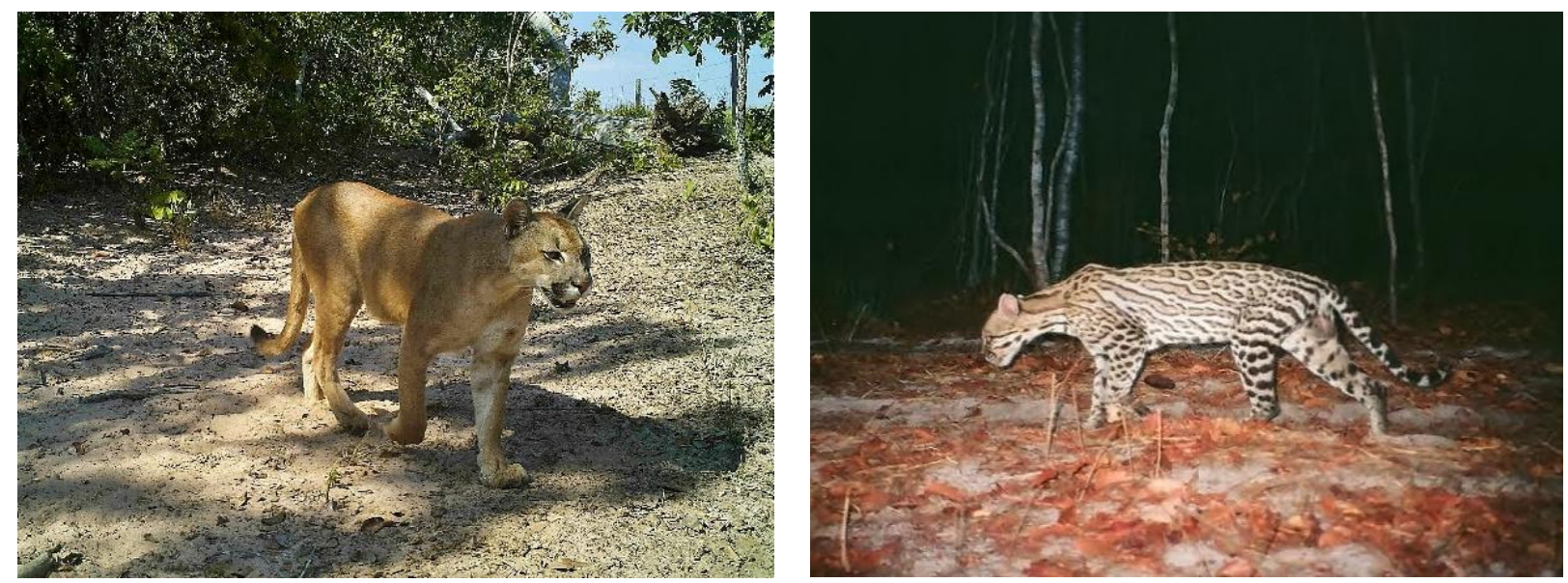

Figura 1. A onça-parda (Puma concolor) e a jaguatirica (Leopardus pardalis), assim como os felídeos de maneira geral, apresentam hábitos furtivos e são de difícil visualização em campo. As armadilhas fotográficas representam uma excelente alternativa para detecção dessas espécies em inventários de fauna. Fonte: Instituto Onça-Pintada. interessam pelas armadilhas fotográficas. Sua utilização não requer nenhuma autorização especial e proprietários de terra têm utilizado com frequência esta ferramenta na identificação de predadores de espécies de difícil visualização que habitam suas propriedades.

\section{PRÓS E CONTRAS}

A vantagem mais evidente no uso desta tecnologia é a possibilidade de monitoramento contínuo alheio à interferência ocasionada pela presença do pesquisador, um aspecto importante no de rebanhos ou mesmo para obter imagens 
estudo de espécies discretas e de difícil detecção (Figura 1). Essa possibilidade é ainda mais vantajosa em ambientes florestais, sobretudo na região Neotropical que apresenta elevada riqueza de espécies. Espécies florestais são geralmente furtivas e a visibilidade neste ambiente é baixa devido à vegetação densa e às condições climáticas muitas vezes adversas.

Foi assim, por exemplo, que o cachorro-do-mato-vinagre (Speothos venaticus), uma espécie extremamente furtiva e de difícil observação em campo, foi registrado em uma reserva de Mata Atlântica no estado de São Paulo (Beisiegel, 2009).

Além disso, é possível utilizar inúmeras câmeras simultaneamente, resultando em um esforço que seria humanamente impossível de ser aplicado considerando os aspectos logísticos e financeiros envolvidos em uma pesquisa de longo prazo. Isso significa que é possível amostrar simultaneamente grandes áreas, por longos períodos de tempo e com demandas de pessoal relativamente baixas. As armadilhas fotográficas também são ferramentas ideais para a amostragem de áreas remotas, uma vez que não precisam ser acessadas diariamente.

As informações obtidas pelas armadilhas fotográficas permitem uma ampla série de análises. Uma característica importante das armadilhas é a capacidade de registrarem a data, o horário e, em alguns modelos, a temperatura e fase da lua no momento da foto. Essas informações permitem determinar com facilidade os padrões de atividade e alguns aspectos do comportamento das espécies. Uma vez que os locais exatos dos registros são conhecidos, os dados resultantes permitem a análise dos padrões espaciais de ocorrência das espécies dentro de um contexto de ecologia da paisagem.

O cálculo do esforço amostral é relativamente simples e, normalmente, expresso em número de dias acumulados em que cada armadilha esteve operacional no campo (ou todas armadilhas, no caso do esforço total). Na prática, não é raro o esgotamento das baterias (pilhas) em algumas unidades antes da sua substituição, o que pode gerar lacunas de amostragem e dificuldades em se determinar exatamente quando a câmera 
deixou de funcionar. Entretanto, algumas câmeras podem ser programadas para tirar uma foto de teste todos os dias, de modo que o último dia em que a câmera funcionou pode ser determinado.

Análises refinadas podem ser feitas para estimar parâmetros populacionais de espécies que possuem marcas individuais, como listras, manchas naturais (Figura 2) ou tags artificiais. Nesses casos, as armadilhas produzem as informações necessárias para aplicar modelos de captura-recaptura e estimar a abundância e densidade da população com dados estatisticamente robustos.

A limitação mais óbvia para utilização deste método é o alto custo inicial para aquisição das câmeras. Numa consulta rápida em um site de vendas com diversas marcas e modelos, os valores

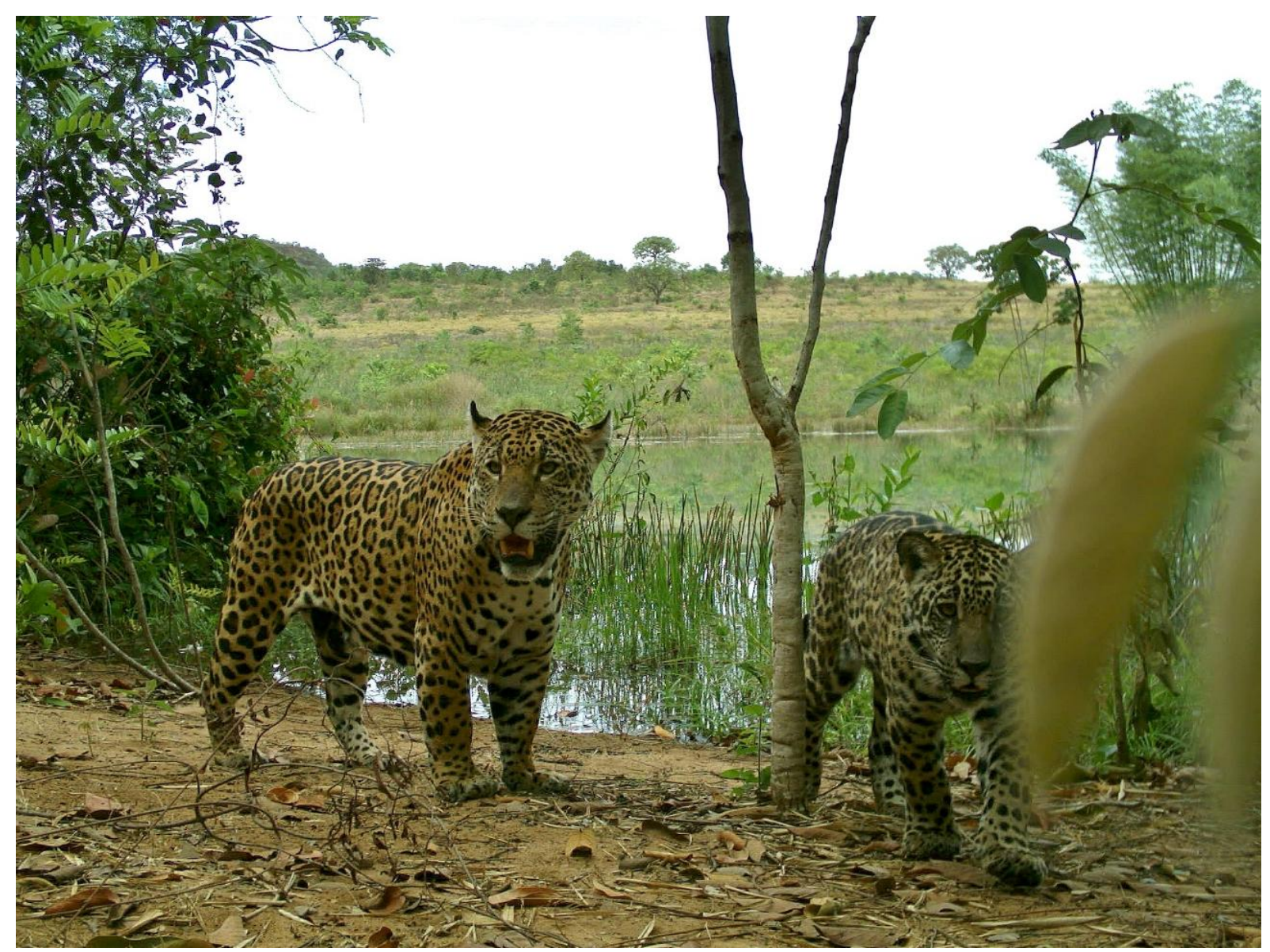

Figura 2. Algumas espécies possuem marcas naturais individuais na pelagem, o que permite a estimativa de parâmetros populacionais fundamentais para medidas de conservação. $\mathrm{Na}$ foto, duas onças-pintadas (Panthera onca) fotografadas às margens do rio Jacuba, no Parque Nacional das Emas. Fonte: Instituto Onça-Pintada. 
variaram de $\mathrm{R} \$ 190,00$ até $\mathrm{R} \$ 2.856,00$ por unidade. Além do preço do equipamento em si, devem ser considerados os custos relacionados à manutenção e funcionamento, incluindo pilhas, cartões de memória, armazenamento e backup das imagens em discos rígidos externos e toda a logística envolvida na instalação e revisão. Estes fatores logísticos influenciam a quantidade de profissionais necessários para a condução de um estudo com armadilhas fotográficas. Dependendo do número de armadilhas e do tempo de amostragem, as câmeras podem gerar uma grande quantidade de dados, sendo necessária a formação de uma equipe capaz de identificar e planilhar os dados com eficiência.

Sua aplicação, como dito anteriormente, é restrita à amostragem de animais de médio e grande porte, com raras exceções. Uma delas é o monitoramento de ninhos de aves que, uma vez localizados, fazem das armadilhas fotográficas a ferramenta ideal para acompanhar o comportamento das espécies.
A maioria das espécies de roedores e marsupiais, por exemplo, é geralmente muito pequena para que características diagnosticáveis sejam captadas pelas imagens. Além disso, esses animais se movem com maior facilidade entre a vegetação densa e, dessa forma, são menos propensos a passar na frente das câmeras. Limitações também surgem no estudo de espécies predominantemente arborícolas, como primatas e esquilos, pois raramente são detectadas pelas armadilhas e, mesmo quando capturadas, as inferências possíveis a partir desses dados são limitadas. $\mathrm{O}$ mesmo vale para a maioria dos mamíferos semiaquáticos.

Um outro ponto importante e que muitas vezes não é ponderado no delineamento de um estudo é a presença humana, mesmo nas áreas mais remotas e de difícil acesso. Não pelo simples fato da presença em si e a possibilidade de registrar uma pessoa nas fotografias, mas sim pela probabilidade de roubo do equipamento.

Minha experiência e a de colegas com armadilhas fotográficas sempre resultou em baixas ocasionadas por roubo. 

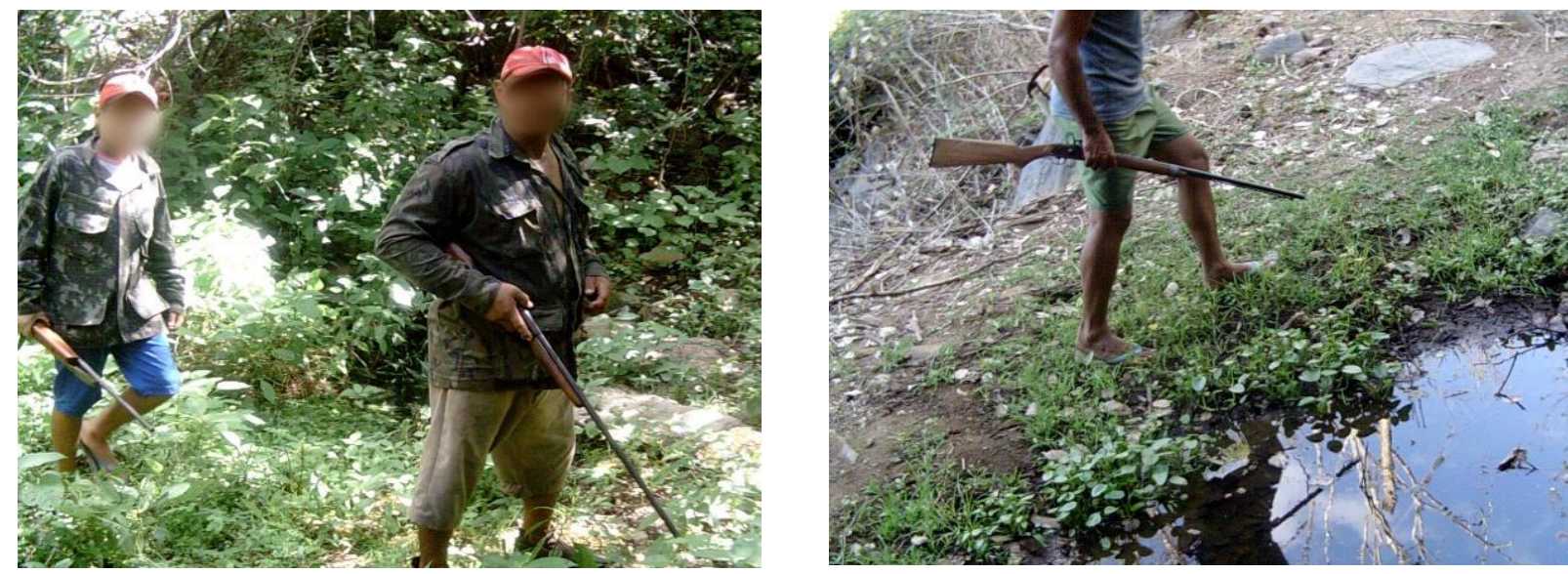

Figura 3. Caçadores são frequentemente fotografados pelas armadilhas fotográficas, como nessas fotos obtidas no interior do Ceará e da Paraíba. Dependendo do local de estudo, o delineamento da pesquisa deve levar em conta a perda de equipamentos por roubo. Fonte: Ubaid, FK.

Tive uma experiência recente durante o monitoramento de uma espécie de ave ameaçada e muito caçada na caatinga, a jacucaca (Penelope jacucaca). O trabalho foi conduzido em algumas localidades no interior do Ceará e da Paraíba, e um dos métodos alternativos para a pesquisa foi o uso de armadilhas fotográficas, que por sinal apresentou excelentes resultados. Já não restam grandes áreas preservadas e as poucas existentes tem a presença constante de pessoas, que muitas vezes habitam as imediações dessas áreas. O saldo, após três anos e meio de monitoramento, foi de $30 \%$ das armadilhas roubadas, ao que tudo indica por caçadores. Aliás, essa foi a única "espécie" registrada em todas as armadilhas (Figura 3).
Colegas que estão atualmente estudando as onças-pintadas (Panthera onca) na Floresta Nacional de Carajás, no Pará, tiveram 38\% das câmeras roubadas no primeiro mês de estudo. E muitas delas instaladas no interior da reserva, em locais de difícil acesso.

Muitos profissionais preferem fixar as armadilhas em árvores grandes com correntes e cadeados, o que não impede muitas vezes o ladrão de derrubar a árvore ou danificar o equipamento, caso não consiga levá-lo.

Esses números são importantes $\mathrm{e}$ devem ser ponderados no delineamento de qualquer pesquisa com o uso desses equipamentos. As áreas preservadas estão sendo gradativamente destruídas, o 
número de pessoas está aumentando e a conscientização sobre a importância desse tipo de pesquisa parece estar longe de algo minimamente aceitável.

Outras questões importantes no delineamento da pesquisa devem incluir o mau funcionamento dos equipamentos, que pode girar entre 3-5\% (experiência própria) e a limitação das baterias, que está diretamente relacionada aos custos envolvidos na sua reposição e em toda logística para revisão das armadilhas.

\section{PERSPECTIVAS}

Os obstáculos e as possibilidades de uso da fotografia remota são múltiplos. Seu potencial para a documentação e $\mathrm{o}$ monitoramento das espécies pode ser usado para responder uma série de questões importantes, especialmente para espécies evasivas e pouco conhecidas pela ciência.

Quando bem delineadas, as pesquisas com armadilhas fotográficas produzem resultados gratificantes e difíceis de se obter com outros métodos.
Para os que atuam na linha de frente da biologia da conservação, há a esperança de que essa tecnologia continue sendo usada para gerar conhecimento científico de qualidade e que a fotografia remota continue promovendo a conservação das espécies e de seus hábitats.

Por fim, agradeço ao Instituto OnçaPintada pelas fotos gentilmente cedidas, em nome de Leandro Silveira e Ananda Barban, e as sugestões sempre valiosas do colega Fábio Maffei.

\section{REFERÊNCIAS}

Beisiegel BM. 2009. First camera trap records of bush dogs in the state of São Paulo, Brazil. Canid News 12.5. Disponível em: $<$ http://www.canids.org/canidnews/12/Bush_do gs_in_Sao_Paulo.pdf $>$. Acesso em 12/09/2017.

Bowkett AE, Rovero F, Marshall AR. 2007. The use of camera-trap data to model habitat use by antelope species in the Udzungwa Mountain forests, Tanzania. African Journal of Ecology. 46: 479-487.

Guggisberg CAW. 1977. Early wildlife photographers. New York (NY): Taplinger Publishing Company. 128 p.

Jacomo ATDA, Silveira L, Diniz JAF. 2004. Niche separation between the maned wolf (Chrysocyon brachyurus), the crab-eating fox (Dusicyon thous) and the hoary fox (Dusicyon vetulus) in central Brazil. Journal of Zoology. 262: 99-106. 
Kauffman MJ, Sanjayan M, Lowenstein J, Nelson A, Jeo RM, Crooks KR. 2007. Remote camera-trap methods and analyses reveal impacts of rangeland management on Namibian carnivore communities. Oryx. 41(1): 70-78.

Kinnaird, MF, Sanderson EW, O’Brien TG, Wibisono HT, Woolmer G. 2003. Deforestation trends in a tropical landscape and implications for forest mammals. Conservation Biology. 17: 245-257.

Kucera TE, Barrett RH. 2011. A History of Camera Trapping. In: O'Connell AF, Nichols JD, Karanth KU (eds.) Camera traps in animal ecology: methods and analyses. New York (NY): Springer. p. 9-26.

Witte M. 1931. O guarachaim-photographo. Vozes de Petrópolis. 25(11): 570-576. 